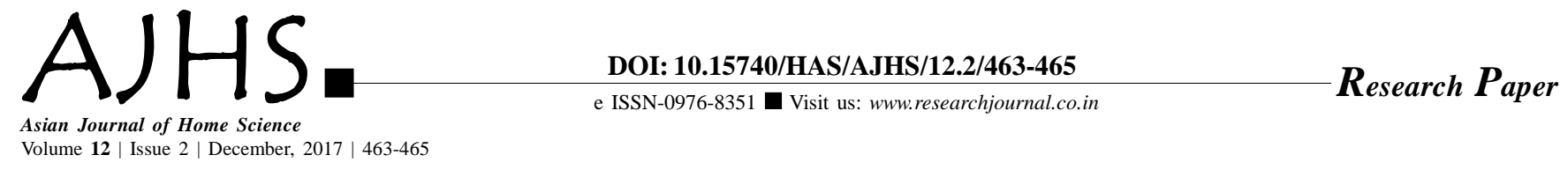

\title{
Change of role of women in agriculture after green revolution in district Hoshiarpur
}

Received: 03.05.2017; Revised: 09.10.2017; Accepted: 23.10.2017

Author for Correspondence

\section{KULVIR KAUR}

Directorate of Extension Education,

Punjab Agricultural University,

LUDHIANA (PUNJAB) INDIA

Email : kulvirkaur70@pau.edu
ABSTRACT : Women are active partners in farming and undertake management along men in addition to their responsibilities at home stead level. The nature and extent of women's involvement in agriculture varies greatly from region to region. The role of woman in agriculture has gone in tremendous change after the advent of green revolution in Punjab. The present study was carried out to assess the change in role of women in agriculture after green revolution in district Hoshiarpur and to assess the factors affecting the change. The findings showed that small and medium land holder women of group I were used to perform all operations. Large land holder women of group I and group II were lesser engaged in all main three operations i.e., farm, subsidiary and allied farm operations.

KEY WORDS: Participation of women, Activities, Land holders

- HOW TO CITE THIS PAPER : Kaur, Kulvir (2017). Change of role of women in agriculture after green revolution in district Hoshiarpur. Asian J. Home Sci., 12 (2) : 463-465, DOI: 10.15740/HAS/AJHS/12.2/ 463-465. 